\title{
Inhibition of lipoxygenase pathway in macrophages co-cultivated with tumor cells
}

\author{
Lido Calorini*, Francesca Bianchini, Antonella Mannini, \\ Gabriele Mugnai, Salvatore Ruggieri \\ Department of Experimental Pathology and Oncology, University of Florence, Florence, Italy
}

Received 28 October 2003; received in revised form 3 September 2004; accepted 13 September 2004

\begin{abstract}
Although there is a great deal of interest in the role played by tumor-associated macrophages in tumor progression, the knowledge of the biological mediators involved in the interplay between macrophages and tumor cells is still limited. In the present study, we investigated whether the lipoxygenase pathway in resident murine peritoneal macrophages is affected by contact with tumor cells of a different origin, e.g. murine B16 melanoma and L929 fibrosarcoma cells, and human Hs294T melanoma and HT1080 fibrosarcoma cells. Our experiments have been carried out by using macrophages co-cultivated with tumor cells at different ratios, in order to simulate the relative proportions between macrophages and tumor cells during the in vivo development of a tumor. Reverse phase HPLC analyses of the lipoxygenase products of resident peritoneal macrophages revealed a rather complex profile characterized by a high level of 12(S)-hydroxyeicosatetraenoic acid and 15(S)-hydroxyeicosatetraenoic acid followed by leukotriene $\mathrm{B}_{4}, 5(\mathrm{~S})$-hydroxyeicosatetraenoic acid, and lipoxins. Macrophages co-cultivated with tumor cells, both murine and human, showed a marked reduction of lipoxygenase products, mainly in the co-cultures where tumor cells prevailed over macrophages. The characteristic profile of macrophage lipoxygenase products was re-established after removal of tumor cells from the co-cultures. The inhibitory effect on lipoxygenase pathways exerted by tumor cells, was not seen when macrophages were co-cultivated with normal primary murine and human fibroblasts.
\end{abstract}

(C) 2004 Elsevier Ireland Ltd. All rights reserved.

Keywords: Murine resident macrophages; Murine melanoma cells; Cell-to-cell interactions; Lipoxygenase metabolites

Abbreviations: LXB4, lipoxin B4,5(S),14(R),15(S)-trihydroxyeicosatetraenoic acid; LXA4, lipoxin A4, 5(S),6(R),15(S)-trihydroxyeicosatetraenoic acid; LTB4, leukotriene B4,5(S),12(R)-dihydroxyeicosatetraenoic acid; 15(S)-HETE, 15(S)-hydroxyeicosatetraenoic acid; 12(S)HETE, 12(S)-hydroxyeicosatetraenoic acid; 5(S)-HETE, 5(S)-hydroxyeicosatetraenoic acid; COX, cyclooxygenase.

* Corresponding author. Address: Dipartimento di Patologia e Oncologia Sperimentali, Università degli Studi di Firenze, Viale G.B. Morgagni 50, 50134 Firenze, Italy. Tel.: + 39554282 322; fax: +39 554282333.

E-mail address: lcalorini@unifi.it (L. Calorini).

0304-3835/\$ - see front matter (C) 2004 Elsevier Ireland Ltd. All rights reserved. doi:10.1016/j.canlet.2004.09.034 


\section{Introduction}

Tumors contain various amounts of inflammatory cells, and a certain percentage of these cells are represented by macrophages, the so-called tumor-associated macrophages [1]. An anti-tumoral role has generally been attributed to tumorassociated macrophages [2-4], but there are also reports that they favor, rather than retard, tumor growth and invasiveness [5-10]. The contrasting effects of macrophages on tumor progression has not been clarified although they might be related to the different amounts of macrophages in the tumoral mass at various stages of tumor growth. A large number of macrophages contributes to the tumoral mass during the early phase of tumor growth, while the number of infiltrating macrophages declines during the development of tumor mass [11-13]. It is conceivable that the different degrees of contact between macrophages and tumor cells during the different stages of tumor growth are relevant to the host cell/tumor cell relationship. Upon contact with tumor cells, macrophages release a range of mediators, including tumor necrosis factor $\alpha[14,15]$, nitric oxide [16,17], prostaglandin $\mathrm{E}_{2}[15,18,19]$. While nitric oxide and tumor necrosis factor $\alpha$ are cytotoxic for tumor cells $[20,21]$, prostaglandin $E_{2}$ facilitates the escape of tumors from immune control by inhibiting $\mathrm{T}$ lymphocyte and macrophage activities [22].

To our knowledge, changes in the lipoxygenase pathway in macrophages upon contact with tumor cells have not yet been explored. In the present study, we investigated whether synthesis of lipoxygenase products in macrophages is affected by contact with tumor cells. Our experimental model consisted in resident murine peritoneal macrophages co-cultivated with murine B16 melanoma cells at different ratios in order to reproduce the relative proportions between tumor cells and macrophages at different times of tumor growth [11-13]. In our experimental protocol, we also included other types of tumor cells, such as murine L929 fibrosarcoma cells, human Hs294T melanoma and HT1080 fibrosarcoma cells. Moreover, we performed experiments by using macrophages cocultivated with normal fibroblasts derived from murine and human primary cultures, in order to ascertain whether the changes in lipoxygenase activity induced by tumor cells represents a tumor-specific rather than a tumor-associated phenomenon.

\section{Materials and methods}

\subsection{Cells and culture conditions}

In the present study, we used the murine B16F10 melanoma (clone F10-M3, [23]) and L929 fibrosarcoma cells (kindly donated by Dr Dello Sbarba, Department of Experimental Pathology and Oncology, University of Florence), human Hs294T melanoma and HT1080 fibrosarcoma cells

Table 1

Lipoxygenase products synthesized by macrophage cultures and by macrophages co-cultivated with F10-M3 melanoma cells

\begin{tabular}{|c|c|c|c|c|c|c|c|}
\hline \multirow{2}{*}{$\begin{array}{l}\text { Lipoxygenase } \\
\text { products }\end{array}$} & \multicolumn{4}{|c|}{ No of cells in macrophage cultures } & \multicolumn{3}{|c|}{ No of cells in macrophage:tumor cell co-cultures ${ }^{a}$} \\
\hline & $\begin{array}{l}31.000 \\
\text { cells } / \mathrm{cm}^{2}\end{array}$ & $\begin{array}{l}62.000 \\
\text { cells } / \mathrm{cm}^{2}\end{array}$ & $\begin{array}{l}124.000 \\
\text { cells } / \mathrm{cm}^{2}\end{array}$ & $\begin{array}{l}200.000 \\
\text { cells } / \mathrm{cm}^{2}\end{array}$ & $\begin{array}{l}62.000 \\
\text { cells } / \mathrm{cm}^{2}\end{array}$ & $\begin{array}{l}124.000 \\
\text { cells } / \mathrm{cm}^{2}\end{array}$ & $\begin{array}{l}200.000 \\
\text { cells } / \mathrm{cm}^{2}\end{array}$ \\
\hline $\mathrm{LXs}^{\mathrm{b}}$ & $3.8^{\mathrm{c}}$ & 2.0 & 2.3 & 1.9 & 1.9 & - & - \\
\hline trans- $\mathrm{LTB}_{4}{ }^{\mathrm{d}}$ & 16.6 & 10.3 & 13.7 & 5.9 & 10.5 & 4.2 & - \\
\hline $\mathrm{LTB}_{4}$ & 14 & 17.5 & 16.2 & 14.1 & 20.1 & 5.7 & - \\
\hline 15(S)-HETE & 43 & 34.3 & 42.2 & 31.6 & 45.1 & 13.5 & 22.8 \\
\hline 12(S)-HETE ${ }^{\mathrm{e}}$ & 210.5 & 215 & 250.2 & 183.5 & 198.6 & 41.3 & 47.6 \\
\hline
\end{tabular}

${ }^{\text {a }}$ All co-cultures contained macrophages and melanoma cells at 1:1 ratio.

${ }^{b}$ LXs represent the sum of $\mathrm{LXA}_{4}, \mathrm{LXB}_{4}$ and their trans isomers.

c Values are $\mathrm{ng} / 10^{6}$ macrophages.

${ }^{\mathrm{d}}$ trans- $\mathrm{LTB}_{4}$ represent the sum of 6-trans-LTB $\mathrm{LT}_{4}$ and 6-trans-12-epi-LTB $\mathrm{LT}_{4}$

e The profile of the lipoxygenase products also contained very small quantity of 5(S)-HETE, that was not reported in the Table. 
Table 2

Lipoxygenase products synthesized by macrophage cultures and by macrophages cultivated with different amounts of F10-M3 melanoma cells ${ }^{\mathrm{a}}$

\begin{tabular}{lcccc}
\hline $\begin{array}{l}\text { Lipoxygenase } \\
\text { product }\end{array}$ & $\begin{array}{l}\text { Macrophage } \\
\text { culture }\end{array}$ & \multicolumn{3}{l}{$\begin{array}{l}\text { Macrophage:tumor cell } \\
\text { co-cultures }\end{array}$} \\
\cline { 2 - 5 } & & $4: 1^{\mathrm{c}}$ & $1: 1$ & $1: 4$ \\
\hline $\mathrm{LXs}^{\mathrm{d}}$ & $2.0^{\mathrm{e}}$ & 1.3 & - & - \\
${\text { Trans }-\mathrm{LTB}_{4}{ }^{\mathrm{f}}}^{\mathrm{LTB}}$ & 13.1 & 5.3 & - & - \\
$15(S)$-HETE & 22.8 & 7.9 & - & - \\
$12(S)$-HETE & 372.2 & 40.4 & 26.3 & 28.7 \\
\hline
\end{tabular}

a Cellular density in the various cell cultures: 200,000 cells $/ \mathrm{cm}^{2}$.

b The viability of macrophages in the different co-cultures, as evaluated by determining the release of nitric oxide into growth media [27], was found to be unaffected by culture conditions.

${ }^{c}$ Macrophage:tumor cell ratio in the co-culture.

${ }^{d}$ LXs represent the sum of $\mathrm{LXA}_{4}, \mathrm{LXB}_{4}$ and their trans isomers.

e Values are ng/ $10^{6}$ macrophages.

${ }^{\mathrm{f}}$ trans- $\mathrm{LTB}_{4}$ represent the sum of 6-trans- $\mathrm{LTB}_{4}$ and 6-trans-12epi-LTB . $^{2}$

(obtained from ATCC, Rockville, MD). We also used primary cultures of murine fibroblasts isolated in our laboratory from C57B1/6 mice, and human skin fibroblasts (donated by Dr Monti, Department. of Experimental Pathology and Oncology, University of Florence). Cells were cultivated in Dulbecco's Modified Eagle Medium (DMEM 4500, GIBCO) supplemented with $10 \%$ fetal calf serum (FCS) (Boerhinger Mannheim, Germany), at $37^{\circ} \mathrm{C}$ in a $10 \% \mathrm{CO}_{2}$ humidified atmosphere. Cells were propagated using a solution of trypsin-EDTA.

\subsection{Preparation of co-cultures of macrophages with tumor cells or normal cells}

Cultures of resident macrophages were established from lavages of the peritoneal cavities of 6-8 week old C57B1/6 mice, as described in a previous paper [24]. In our experiments, we used: (a) macrophage cultures at different densities; (b) macrophage:tumor cell cocultures at a 1:1 ratio, but at different cell densities; (c) high density macrophage:tumor cell co-cultures at different ratios (from 4:1 to 1:4); (d) high density macrophage:normal cell co-cultures at 1:1 ratio. Macrophage cultures and co-cultures were maintained for $18 \mathrm{~h}$ in a medium containing $250 \mu \mathrm{g} / \mathrm{ml} \mathrm{BSA}$, at $37^{\circ} \mathrm{C}$, in a $10 \% \mathrm{CO}_{2}$ humidified atmosphere.

\subsection{Analysis of lipoxygenase products}

The analysis of lipoxygenase products were performed on cultures which were incubated at $37^{\circ} \mathrm{C}$ for 20 min with arachidonic acid $(20 \mu \mathrm{M})$ and calcium ionophore A23187 $(5 \mu \mathrm{M})$ in a pre-warmed PBS solution at $\mathrm{pH} 7.45$ containing $\mathrm{Ca}^{++}(1.0 \mathrm{mM})$ and $\mathrm{Mg}^{++}(0.8 \mathrm{mM})$ chlorides. The reaction was stopped by adding 2 volumes of cold methanol containing $100 \mathrm{ng}$ of $\mathrm{PGB}_{2}$, as internal standard, transferred into plastic tubes and mantained for $2 \mathrm{~h}$ in ice. After precipitation of the proteinaceus material by centrifugation, the reaction mixture was transferred into roundbottom flasks and evaporated under vacuum. The residue was resuspended in $10 \mathrm{ml}$ of methanol- $\mathrm{H}_{2} \mathrm{O}$ (1:45; vol:vol) by vortexing, acidified to $\mathrm{pH} 3.5$ with

Table 3

Lipoxygenase activity in macrophage coltures upon the removal of tumor cells ${ }^{\mathrm{a}}$

\begin{tabular}{|c|c|c|c|c|c|}
\hline \multirow[t]{2}{*}{ Culture } & \multicolumn{5}{|c|}{ Lipoxygenase products } \\
\hline & $\mathrm{LXs}^{\mathrm{b}}$ & trans-LTB ${ }_{4}{ }^{\mathrm{c}}$ & $\mathrm{LTB}_{4}$ & 15(S)-HETE & 12(S)-HETE \\
\hline Macrophage culture & $1.6^{\mathrm{d}}$ & 7.7 & 14.1 & 62.7 & 308.0 \\
\hline Macrophage:tumor cell co-culture & - & - & - & 9.4 & 14.0 \\
\hline Macrophages freed from tumor cells ${ }^{\mathrm{e}}$ & 2.1 & 11.8 & 14.5 & 72.9 & 335.5 \\
\hline
\end{tabular}


$0.1 \mathrm{~N} \mathrm{HCl}$, and then rapidly loaded onto a $\mathrm{C} 18$ reverse phase cartridge (C18 Plus Sep-Pak, Waters Associates). The cartridge was eluted with $n$-hexane followed by methyl formate and methanol. The methyl formate fraction containing $\mathrm{LTB}_{4}$, LXs, and monoHETEs, was evaporated under a stream of nitrogen and the residue, resuspended in a small volume of methanol, was chromatographed on a LiChrospher 100 RP-18 column
$(4.6 \mathrm{~mm} \times 25 \mathrm{~cm}, 5-\mu \mathrm{m}$ particles, LiChroCART, Merck) mounted in a Perkin Elmer, Model 250, HPLC apparatus. Chromatography was performed at room temperature by using a $19 \mathrm{~min}$ isocratic elution in solvent A (methanol: $\mathrm{H}_{2} \mathrm{O}$ :acetic acid; 65:35:0.01, v/v), followed by a 1 min linear gradient from $100 \%$ solvent A to $100 \%$ solvent $\mathrm{B}$ (methanol: $\mathrm{H}_{2} \mathrm{O}$ :acetic acid; $75: 25: 0.01, \mathrm{v} / \mathrm{v}$ ), and a $40 \mathrm{~min}$ isocratic elution in
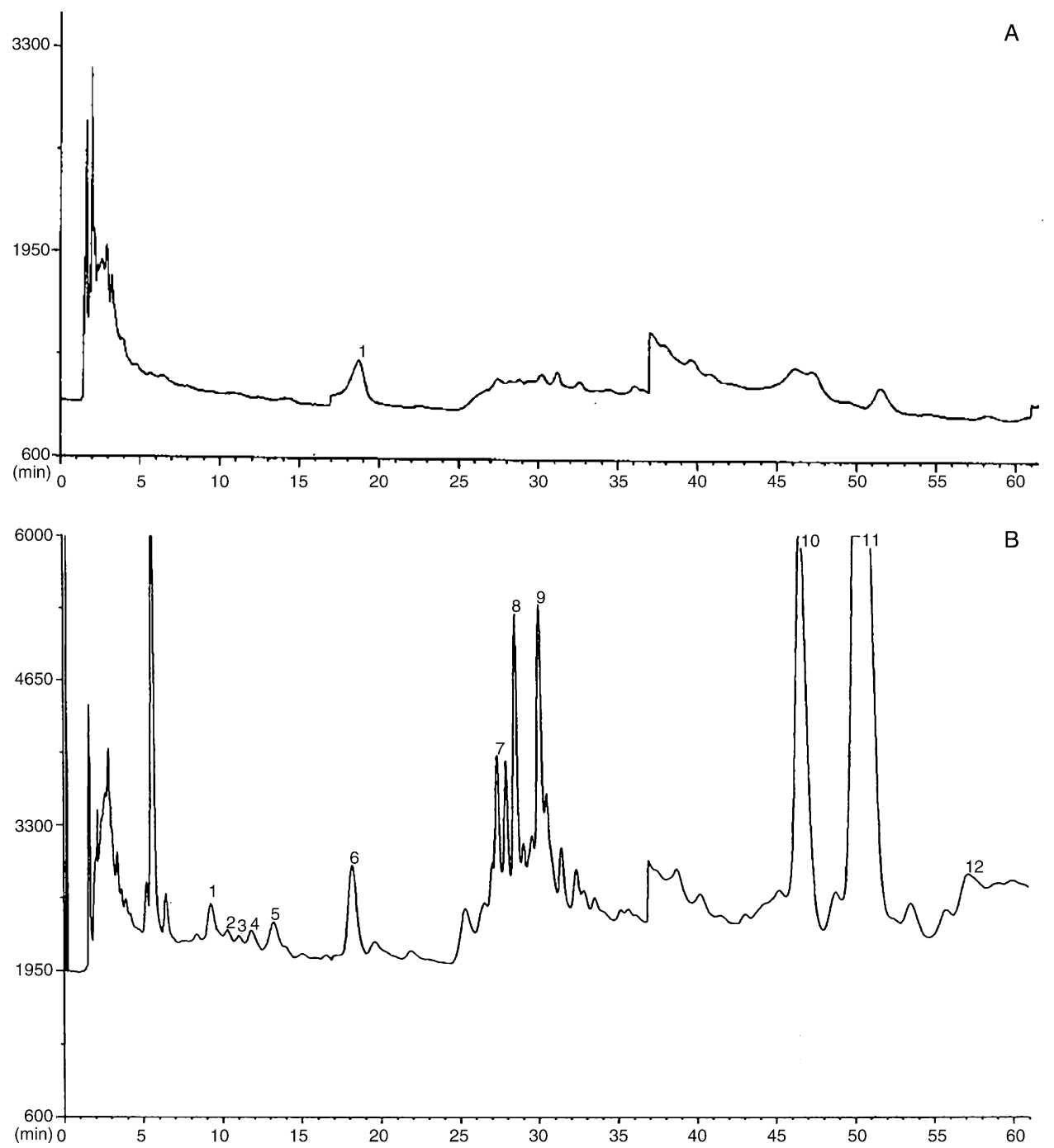

Fig. 1. RP-HPLC profiles of lipoxygenase products synthetized by murine F10-M3 melanoma cells* (A) and by resident murine peritoneal macrophages (B). (1: trans-LXB 4 , 2: LXB $;$; 3: trans-LXA $;$;: LXA $;$;: $\mathrm{PGB}_{2} ;$ 6: 6-trans-LTB 4 ; 7: 6-trans-12-epi-LTB $;$; 8: LTB 4 ; 9:15(S)HETE; 10: 12(S)-HETE; 11: 5(S)-HETE). 

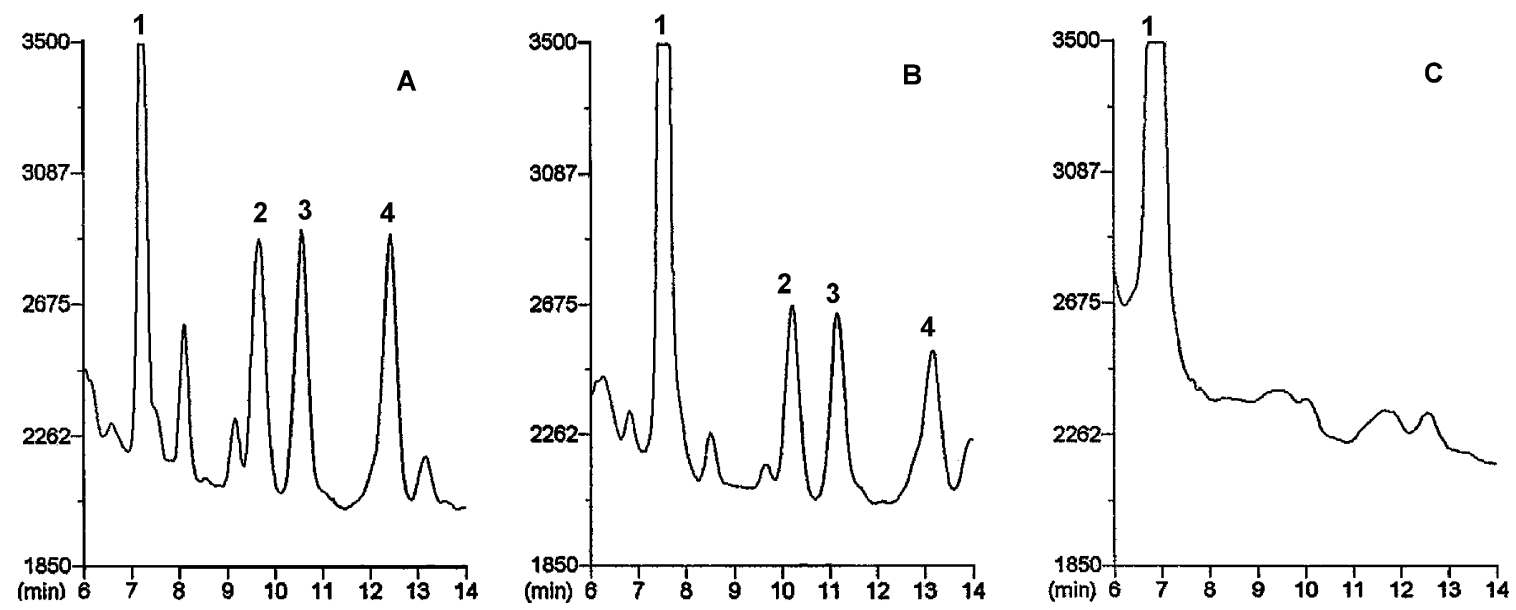

Fig. 2. RP-HPLC profiles of leukotrienes produced by resident murine peritoneal macrophages (A), by macrophage: murine fibroblast cocultures (B), by macrophage:murine L929 fibrosarcoma cell co-cultures (C). Cellular density in the cultures were 150,000 cells $/ \mathrm{cm}^{2}$; ratio in cocultures was 1:1. In our experimental conditions murine fibroblasts and fibrosarcoma cells showed no generation of leukotrienes. Chromatography were performed at room temperature using a 40 min isocratic elution in $100 \%$ solvent B. (1: $\mathrm{PGB}_{2} ; 2$ : 6-trans-LTB 4 ; 3: 6trans-12-epi-LTB 4 ; 4: $\mathrm{LTB}_{4}$ ).

solvent B. Flow rate was $1.0 \mathrm{ml} / \mathrm{min}$ during the whole run. The effluents were analyzed with a photodiode array rapid spectral detector (Model 235, Perkin Elmer). Lipoxygenase products in the chromatograms were identified by comparison with authentic standards and verified by spectra analysis [25,26]. The levels of lipoxygenase products were determined by the use of calibration curves constructed with authentic standards, and the values were corrected by the recovery of the $\mathrm{PGB}_{2}$.

Data reported in Tables 1-3, Figs. 2 and 3 derived from a representative experiment of 3-4.

\section{Results}

Fig. 1 gives the RP-HPLC profile of lipoxygenase products synthesized by cultures of B16 melanoma cells and murine resident peritoneal macrophages. The profile of lipoxygenase products of macrophage cultures was characterized by high levels of 12-HETE and 15-HETE, followed by $\mathrm{LTB}_{4}, 5$-HETE, and LXs. In our experimental conditions tumor cells showed no generation of lipoxygenase products. Table 1 presents the profile of lipoxygenase products of macrophages co-cultivated with tumor cells at a 1:1 ratio compared with that of macrophage cultures. Macrophage cultures at different densities generated comparable amounts of lipoxygenase products. Macrophage:tumor cell co-cultures at low densities synthesized the same amount of lipoxygenase products as those found in macrophage cultures. On the other hand, a marked reduction of HETEs, accompanied by a lack of $\mathrm{LTB}_{4}$ and LXs, was found in high density co-cultures $\left(200.000\right.$ cells $\left./ \mathrm{cm}^{2}\right)$. Table 2 gives the profiles of lipoxygenase products generated by macrophages cocultivated with tumor cells at different ratios. The reduction of lipoxygenase products found in 1:1 macrophage:tumor cell co-cultures was still more evident in 1:4 co-cultures, while in $4: 1$ co-cultures this reduction was rather limited. As shown in Table 3, macrophage lipoxygenase activity promptly recovered after tumor cells were removed from the cocultures.

As shown in Fig. 2, co-cultivation with L929 fibrosarcoma cells also inhibited macrophage leukotriene production, which, however, was not affected by the presence of murine skin fibroblasts. A similar different effect was found in leukotriene synthesis in macrophages co-cultivated with human tumoral (Hs294T melanoma and HT1080 fibrosarcoma cells) and normal fibroblasts (Fig. 3). 

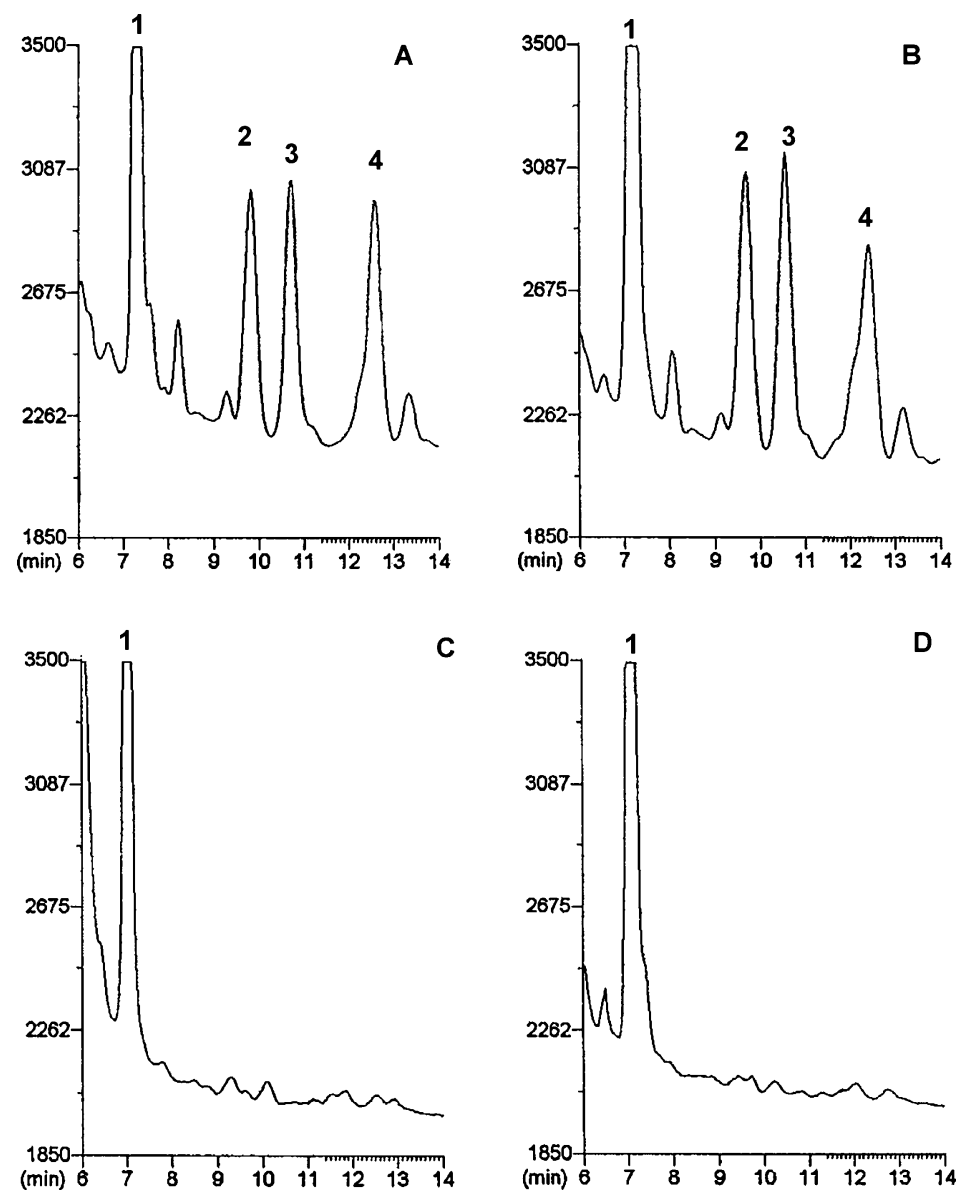

Fig. 3. RP-HPLC profiles of leukotrienes produced by resident murine peritoneal macrophages (A), by macrophage:human fibroblast cocultures (B), by macrophage:human Hs294T melanoma cell co-cultures (C), by macrophage:human HT1080 fibrosarcoma cell co-cultures (D). Cellular density in the cultures were 150,000 cells $/ \mathrm{cm}^{2}$; ratio in co-cultures was $1: 1$. In our experimental conditions human fibroblasts and tumor cells showed no generation of leukotrienes. Chromatography were performed at room temperature using a 40 min isocratic elution in $100 \%$ solvent B. (1: $\mathrm{PGB}_{2} ; 2$ : 6-trans-LTB $;$; 3: 6-trans-12-epi-LTB 4 ; $\left.4: \mathrm{LTB}_{4}\right)$.

\section{Discussion}

Using an experimental model represented by macrophages cultivated together with tumor cells at different ratios, we sought to explore the extent to which lipoxygenase activity of macrophages in the tumor mass is influenced by contact with tumor cells.

Data obtained by using our experimental model indicated that the lipoxygenase pathway in macrophages is inhibited upon contact with tumor cells. Under the same experimental conditions, tumor cells did not generate lipoxygenase products. We also found that the subtraction of arachidonic acid from the reaction mixture by tumor cells was negligible (data not shown), an observation that appears to rule out that the decreased synthesis of lipoxygenase products in macrophages co-cultivated with tumor cells is due to metabolic competition between macrophages and tumor cells.

Two interacting variables proved to be critical for the inhibition of lipoxygenase activity in macrophages co-cultivated with tumor cells: high cell density and low macrophage:tumor cell ratio. It is possible that these variables provide a tight contact between 
macrophages and tumor cells, a condition that might occur in late stages of tumor growth. The inhibition of lipoxygenase activity induced by tumor cells on macrophages appeared to be a reversible phenomenon since this activity was completely recovered after tumor cells were removed from the co-cultures. The fact that lipoxygenase activity was not modified in macrophages grown in media conditioned by tumor cells strengthens the requirement of a tight contact between the two cell types in order to inhibit macrophage lipoxygenase activity (data not shown). The tumor-inhibiting effect on macrophage lipoxygenase activity appeared to be a tumor-specific phenomenon, in view of the findings that macrophage lipoxygenase activity was inhibited by human or murine melanoma and fibrosarcoma cells, but not by normal human or murine fibroblasts.

The inhibitory effect of tumor cells on the lipoxygenase activity of macrophages might be important in tumor progression due to the depletion of lipoxygenase products in the tumoral microenvironment. In fact, the reduction of $\mathrm{LTB}_{4}$, an important stimulator of chemiotaxis and cytotoxicity of macrophages [28-30], deprives host tissues of an efficient defense against tumors. The depletion in the tumoral microenvironment of another chemotactic factor for monocytes [31-33], the lipoxins, may contribute to the reduced resistance against tumor growth. Moreover, the inhibition of lipoxygenase activity might favour tumoral neoangiogenesis, in view of the recent finding that a COX-2 product is converted by 5-lipoxygenase into lipoxins with antiangiogenic activity [34]. Thus, the block of synthesis of $\mathrm{LTB}_{4}$ and lipoxins in macrophages upon contact with tumor cells might represent a mechanism used by tumor cells to escape from host defence. However, an opposite effect might be produced by the disappearance of 12(S)-HETE from the macrophage lipoxygenase profile. In fact, the block of 12(S)-HETE generation by macrophages deprives the tumoral microenvironment of a mediator which promotes invasiveness by influencing various steps of the 'metastatic cascade' [35]. Thus, the net effect of the tumor-induced block of the macrophage lipoxygenase pathway remains elusive. In view of the different capacity of various anatomical compartments to secrete lipoxygenase products of macrophages [36, 37], the effect of the tumor-induced block of the macrophage lipoxygenase pathway on tumor growth might depend on the lipoxygenase profile characteristic of the tissue-specific macrophages.

\section{Acknowledgements}

The study was supported by grants from MURST 40\% Cofin 1999 and MURST ex 60\%.

\section{References}

[1] A. Mantovani, C. Ballotta, B. Abdeljalil, B. Bottazzi, Origin and regulation of tumor-associated macrophages: the role of tumor-derived chemotactic factor, Biochim. Biophys. Acta 865 (1986) 59-67.

[2] P. Alexander, The functions of the macrophage in malignant disease, Annu. Rev. Med. 27 (1976) 207-224.

[3] I.J. Fidler, A.J. Schroit, Recognition and destruction of neoplastic cells by activated macrophages: discrimination of altered self, Biochim. Biophys. Acta 948 (1998) 151-173.

[4] P.W. Whitworth, C.C. Pak, J. Esgro, E.S. Kleinerman, I.J. Fidler, Macrophages and cancer, Cancer Metastasis Rev. $8(1989 / 1990)$ 319-351.

[5] A. Gabizon, S.J. Leibovich, R. Goldman, Contrasting effects of activated and nonactivated macrophages and macrophages from tumor-bearing mice on tumor growth in vivo, J. Natl Cancer Inst. 65 (1980) 913-920.

[6] E. Gorelik, R.H. Wiltrout, M.J. Brunda, W.E. Brende, R.B. Herberman, Augmentation of metastasis formation by thioglycollate-elicited macrophages, Int. J. Cancer 29 (1982) $575-581$.

[7] H. Mashiba, K. Matsunaga, Inhibition and augmentation of lymphoma metastasis by adoptively transferred peritoneal macrophages in hamster, Cancer Lett. 33 (1986) 11-18.

[8] M. Mukai, K. Shinkai, R. Tateishi, R. Mori, H. Hakedo, Macrophage potentiation of invasive capacity of rat ascites hepatoma cells, Cancer Res. 47 (1987) 2167-2171.

[9] H. Akedo, K. Shinkai, M. Mukai, K. Komatsu, Potentiation and inhibition of tumor cell invasion by host cells and mediators, Invasion Metastasis 9 (1989) 134-148.

[10] O. Cecconi, L. Calorini, A. Mannini, G. Mugnai, S. Ruggieri, Enhancement of lung-colonizing potential of murine tumor cell lines co-cultivated with activated macrophages, Clin. Exp. Metastasis 15 (1997) 94-101.

[11] S.J. Normann, Macrophage infiltration and tumor progression, Cancer Metastasis Rev. 4 (1985) 277-291.

[12] P.J. Bugelski, R.L Kirsh, J.M. Sowinski, G. Poste, Changes in the macrophage content of lung metastases at different stages in tumor growth, Am. J. Pathol. 118 (1985) 419-424.

[13] P.J. Bugelski, S. Corwin, S. North, R.L. Kirsh, G.L. Nicolson, G. Poste, Macrophage content of spontaneous metastases at different stages of growth, Cancer Res. 47 (1987) 4141-4145.

[14] R. Janicke, D.N. Mannel, Distinct tumor cell membrane constituents activate human monocytes for tumor necrosis factor synthesis, J. Immunol. 14 (1990) 1144-1150. 
[15] J.D. Hasday, E.M. Shah, A.P. Liebermann, Macrophage synthesis of tumor necrosis factor-alpha release is induced by contact with some tumors, J. Immunol. 145 (1990) 371-379.

[16] M. Zembala, M. Siedlar, J. Marcinkiewicz, J. Pryjma, Human monocytes are stimulated for nitric oxide release in vitro by some tumor cells but not by cytokines and lipopolysaccharide, Eur. J. Immunol. 24 (1994) 35-439.

[17] M. Siedlar, B. Mytar, A. Krzeszowiak, J. Baran, M. Hyszko, I. Ruggiero, et al., Demonstration of iNOS-mRNA and iNOS in human monocytes stimulated with cancer cells in vitro, J. Leuk. Biol. 65 (1999) 597-604.

[18] K.H. Leung, D.G. Fisher, H.S. Koren, Erythromyeloid tumor cells (K562) induce PGE synthesis in human peripheral blood monocytes, J. Immunol. 13 (1983) 445-449.

[19] A.P. Malick, K.D. Elgert, R. Garner, N.F. Adkinson Jr., Prostaglandin E2 production by Mac-2+ macrophages: tumorinduced population shift, J. Leuk. Biol. 42 (1987) 673-681.

[20] E.A. Carswell, L.J. Old, R.L. Kassel, S. Green, N. Fiore, B. Williamson, An endotoxin-induced serum factor that causes necrosis of tumors, Proc. Natl Acad. Sci. USA. 72 (1975) 3666-3670.

[21] J.B. Hibbs Jr., R.R. Taintor, Z. Vavrin, Macrophage cytotoxicity: role for $\mathrm{L}$-arginine deiminase and imino nitrogen oxidation to nitrite, Science 235 (1987) 473-476.

[22] M.R.I. Young, Eicosanoids and the immunology of cancer, Cancer Metastasis Rev. 13 (1994) 337-348.

[23] S. Gattoni-Celli, L. Calorini, M.M. Simile, S. Ferrone, Modulation by MHC Class I antigens of the biology of melanoma cells. Non-immunological mechanisms, Melanoma Res. 3 (1993) 285-289.

[24] L. Calorini, A. Mannini, F. Bianchini, G. Mugnai, S. Ruggirei, The change in leukotrienes and lipoxins in activated mouse peritoneal macrophages, Biochim. Biophys. Acta 1484 (2000) 87-92.

[25] B. Samuelsson, S-E. Dahlen, J.A. Lindgren, C.A. Rouzer, C.N. Serhan, Leukotrienes and lipoxins: Structures, biosynthesis, and biological effects, Science 237 (1987) 1171-1175.

[26] C.N. Serhan, K.C. Nicolaou, S.E. Webber, C.A. Veale, SE. Dahlen, T.J. Puustinen, et al., Stereochemistry and biosynthesis, J. Biol. Chem. 261 (1986) 16340-16345.

[27] B. Aggarwal, K. Mehta, The determination and regulation of nitric oxide production from macrophages lipopolysaccharides, cytokines, and retinoids, Methods Enzymol 269 (1996) 166-171.
[28] M. Rola-Pleszczynski, I. Lemaire, Leukotriens augment interleukin 1 production by human monocytes, J. Immunol. 135 (1985) 3958-3961.

[29] L. Gagnon, L.G. Fillon, C. Dubois, M. Rola-Pleszczynski, Leukotriens and macrophage activation: Augmented cytotoxicity activity and enhanced interleukin 1 , tumor necrosis factor and hydrogen peroxide production,, Agents Actions 26 (1989) 141-147.

[30] L. Gagnon, L.G. Fillon, M. Rola-Pleszczynski, Enhanced production of tumor necrosis factor (TNF)-alpha by human monocytes exposed to leukotriene B4, Int. J. Immunopathol. Pharmacol. 2 (1989) 155-163.

[31] J.F. Maddox, C.N. Serhan, Lipoxin A4 and B4 are potent stimuli for human monocyte migration and adhesion: Selective inactivation by dehydrogenation and reduction, J. Exp. Med. 183 (1996) 137-146.

[32] J.F. Maddox, M. Hachicha, T. Takano, N.A. Petasis, V.V. Fokin, C.N. Serhan, Lipoxin A4 stable analogs are potent minetics that stimulate human monocytes and THP-1 cells via a G-protein-linked lipoxin A4 receptor, J. Biol. Chem. 276 (1997) 6972-6978.

[33] J.F. Maddox, S.P. Colgan, C.B. Clish, N.A. Petasis, V.V. Fokin, C.N. Serhan, Lipoxin B4 regulates human monocyte/neutrophil adherence and motility: design of stable lipoxin B4 analogs with increased biologic activity, FASEB J. 12 (1998) 487-494.

[34] I.M. Fierro, J.L. Kutok, C.N. Serhan, Novel lipid mediator regulators of endothelial cell proliferation and migration: aspirin-triggered-15R-lipoxin A4 and lipoxin A4, J. Pharmacol. Exp. Ther. 300 (2002) 385-392.

[35] K.V. Honn, D.G. Tang, X. Gao, I.A. Butovich, B. Liu, J.W. Timar, W. Hagmann, 12-lipoxygenases and 12(S)HETE: role in cancer metastasis, Cancer Metastasis Rev. 13 (1994) 365-396.

[36] R.J. Ouwendijk, F.J. Zijlstra, A.M. Van den Broek, A. Brouwer, J.H. Wilson, J.E. Vincent, Comparison of the production of eicosanoids by human and rat peritoneal macrophages and rat Kupffer cells, Prostaglandins 35 (1988) 437-446.

[37] T.G. Brock, E. Maydanski, R.W. McNish, M. Peters-Golden, Co-localization of leukotriene A4 hydrolase with 5-lipoxygenase in nuclei of alveolar macrophages and rat basophilic leukemia cells but not neutrophils, J. Biol. Chem. 276 (2001) 35071-35077. 